\title{
Refugiados: necesidad de una revisión
}

\section{Antoni Lluch}

Centre d'Informacio i Documentació Internacionals a Barcelona (CIDOB)

Elisabets, 12.08001 Barcelona. Spain

\section{Resumen}

El artículo trata de los refugiados y sus derechos. Analiza comparativamente su situación en diversos países y en España.

Palabras clave: refugiados, inmigración económica, inmigración europea, políticas de asilo.

Abstract. Refugees: the need of revising a situation

The article deals with refigees and their rights in receiving countries. It analyses their situaton in differen European countries and in Spain.

Key words: refugees, economic immigration, european immigration, asile policies.

En toda Europa la política sobre los refugiados va siendo cada vez más restrictiva, limitándose el acceso al refugio y los derechos de los solicitantes y refugiados.

Un repaso a las estadísticas de los últimos af́os en distintos países europeos, así lo demuestra.

Del informe del ECRE (European Consultation on Refugees and Exiles) presentado en Berlín en abril de 1993 por representantes de ONG de distintos países, obtenemos los datos sobre reconocimientos de asilo en 1992:

\begin{tabular}{lc}
\hline País & \% de reconocimientos \\
\hline Austria & 9,7 \\
Francia & 29 \\
Alemania & 4,25 \\
Italia & 3,7 \\
Holanda & 14,1 \\
España & 4 \\
Suecia & 35 \\
Reino Unido & 3,3 \\
\hline
\end{tabular}


Exceptuando el caso de Francia, los porcentajes de reconocimiento de refugiados en los países de la CE raramente pasa del $10 \%$. Ello ya contrasta con otros países europeos no comunitarios, como Suecia.

Estas tasas de reconocimiento han sufrido un progresivo descenso en los últimos ańos hasta llegar a los límites actuales, en que dada su escasa dimensión pueden oscilar positivamente o volver a descender en años sucesivos.

\begin{tabular}{llllccc}
\hline Pás & Año 1987 & 1988 & 1989 & 1990 & 1991 & 1992 \\
\hline Aussria & 31 & 27 & 19 & 6,8 & 12,6 & 9,7 \\
Francia & 32,6 & 34,5 & 28 & 15,4 & 19 & 29 \\
España & 31,1 & 22 & 8 & 11 & 4,1 & 4 \\
Alemania & - & - & - & - & 6,9 & 4,2 \\
\hline
\end{tabular}

Datos en tantos por ciento.

Las tasas de reconocimiento de refugiados por países son también sobradamente elocuentes. Dos aspectos que conviene destacar:

- El escaso tanto por ciento de concesiones de refugio a solicitantes de países en conflicto.

- La gran variación en el tanto por ciento de concesiones entre unos países europeos y otros para solicitantes de la misma procedencia.

Porcentajes de reconocimientos de refugio por países de procedencia.

Pás de acogida Reino

País de origen Austria Alemania Italia Suiza Espafia* Suecia Unido

\begin{tabular}{lccccccc}
\hline Bosnia & & & & & & & \\
Herzegovina & 17,6 & 2,2 & - & - & - & - & - \\
Croacia & 0 & - & - & 3,6 & - & 25 & - \\
Fed. Yugoslava & 2,6 & 1,9 & 7,8 & - & - & - & - \\
Argelia & 0 & 0,1 & 0 & 0 & - & - & - \\
Somalia & 14 & - & 4,1 & 0 & 72,3 & 89 & 1 \\
Sudán & 0 & - & 40 & - & - & - & 62,5 \\
Afganissán & 46,6 & 32,1 & 50 & 17,6 & 73,9 & - & - \\
Irán & - & - & 44 & 5,5 & 44,7 & 53 & 14,1 \\
Irakk & 85 & - & 56,5 & 19,2 & 35,7 & 89 & 13,2 \\
Líbano & 3 & - & 33 & 0 & - & 36 & 3,6 \\
Sri Lanka & 2,9 & 24,8 & 7,8 & 1,2 & - & - & 0,9 \\
\hline
\end{tabular}

Fuente: ECRE. Informe 1993. Elaboración propia.

* Daros 1992. Boletin de lnmigración y Refugio, núm. 1, INSERSO, marzo 1993.

Puede llamar poderosamente la arención, cuando menos a la opinión públi$\mathrm{ca}$, el escaso reconocimiento que obtienen en toda Europa los huidos de la antigua Yugoslavia. Igualmente, la efervescencia política en Argelia no tiene traducción en refugiados políticos reconocidos. 
El otro aspecto a destacar es la gran disparidad entre unos países y otros. Los somalíes obtienen un gran reconocimiento en Suecia y España y prácticamente nulo en Italia y Reino Unido. El abismo se da también en otras procedencias como Sudán, Irak o Líbano. No podemos considerar que los afganos llegados a España sean mayoritariamente refugiados, mientras que los solicitantes afganos en Suiza no lo sean.

Estas grandes diferencias significan, pues, orientaciones polfticas distintas. Con la misma Convención de Ginebra y leyes de asilo similares e iguales situaciones políticas, unos países adoptan unas actitudes u otras. Ello es preocupante por la utilización política del refugio, más sujeto a intereses políticos coyunturales que a una apreciación objetiva de los problemas y aplicación consecuente de los instrumentos juŕdicos. También es preocupante cuando se habla de una política europea común sobre el asilo. De las estadísticas dificilimente se desprende una opinión común, sino que hay grandes y graves divergencias. Los intereses particulares nacionales priman por encima de los intereses generales.

Ante la disminución de la concesión de asilo, podríamos preguntarnos si ha disminuido la conflictividad mundial y si no hay motivos para refugiarse. A pesar de la disminución en la concesión del refugio, la prensa se hace eco de manera continua de los problemas políticos que originan refugiados. Cinco o diez años atrás los refugiados raramente ocupaban primeras páginas en los periódicos. Actualmente, se alude constantemente a ellos: kurdos en Turquía, albaneses en Italia, afganos en Pakistán, sudaneses en Etiopía, ex-yugoslavos, armenios, etc. Miles de víctimas y perseguidos que van buscando protección para sobrevivir y un nuevo hogar donde guarecerse.

Justo en el momento en que el fenómeno de los refugiados se producía a las puertas de Europa, ésta endurece la política, protegiéndose de estos flujos, como si pudiera negar la realidad apartándola de sus fronteras. Páises que habían hecho del derecho de asilo una bandera y de las prestaciones sociales a los refugiados un modelo y un orgullo legítimo, han ido girando sus espaldas, endureciendo actitudes al amparo de la crisis económica y de la construcción y cohesión europea.

Este cambio de política ha pasado por etapas sucesivas: dificultades en el acceso y la tramitación en las concesiones, recorte en las prestaciones sociales, expulsiones de los solicitantes rechazados, todo ello para consagrarse posteriormente en cambios legislativos como en Alemania y Francia, o el cambio que puede producirse en España en los próximos meses. El último esiabón en esta política es su plasmación legislativa, que le da un carácter permanente y una cobertura social.

Este endurecimiento progresivo se ha justificado en toda Europa de la misma forma: el abuso que se ha hecho de la vía del refugio por parte de los inmigrantes económicos. La supuesta generosidad del refugio abría las puertas a una inmigración subrepticia. Así, el culpable del cambio legislativo no es ni la insensibilidad política, ni la insolidaridad de la sociedad, ni que las administraciones de los distintos paises estén más preocupadas por unas décimas en unos porcentajes que por centenares de muertos en sus fronteras. El res- 
ponsable de este endurecimiento, el culpable es el propio inmigrante: el que ya es víctima de la miseria económica o de la persecución en su propio país es el culpable en Europa de estos cambios legislativos. Su presencia también es culpable del auge del racismo y la extrema derecha.

Parecería que ni Europa ni los europeos tienen responsabilidad alguna en este fenomeno. No se piensa, ni se actúa: tan solo se reacciona. Dieciocho millones de refugiados en el mundo, un millón en Europa Occidental, con un futuro cada vez más incierto.

No hay porque negar que emigrantes económicos pretenden regularizar su proyecto migratorio en base al estatuto de refugiado, pero ello no es numéricamente significativo ni cualitativamente justifica el cambio.

Hay razones varias para ello:

1. La emigración económica no coincide con la política en la mayoría de países. Hay procedencias muy marcadas en unos y otros. La denegación del refugio por cualquier motivo no significa automáticamente que el denegado sea inmigrante económico.

Podemos observar las principales procedencias de los solicitantes de refugio y los inmigrantes económicos en distintos países europeos. No coinciden unos con otros.

\begin{tabular}{lll}
\hline País & $\begin{array}{l}\text { Procedencia } \\
\text { inmigrantes }\end{array}$ & $\begin{array}{l}\text { Procedencia } \\
\text { solicitantes asilo 1992 }\end{array}$ \\
\hline Alemania & Turquía & Ex-Yugoslavia \\
& Ex-Yugoslavia & Rumania \\
& Marruecos & BuIgaria \\
& Túnez & Turquía \\
Francia & Argelia & Sri ILanka \\
& Marruecos & Zaire \\
& Túnez & Ex-Yugoslavia \\
& Turquia & China \\
& & Vietnam \\
Reino Unido & India & Ex-Yugoslavia \\
& Jamaica & Sri Lanka \\
& Pakistán & Turquía \\
& Bangladesh & Pakistán \\
& Marruecos & Perú \\
& Argentina & R. Dominicana \\
& Filipinas & Polonia \\
& & Senegal \\
& & Rumania \\
\hline
\end{tabular}

Salvo el caso de turcos y ex-yugoslavos en Alemania, éstos, por razones obvias, no tienen coincidencias significativas entre los países originarios de solicitantes de refugio y de inmigrantes económicos, tanto a nivel nacio- 
nal como a nivel común europeo. Los magrebíes, que son mayoritarios en la inmigración económica en Europa, raramente son solicitantes de asilo, al igual sucede con los originarios del sudeste asiático o latinoamericanos. El único caso en el que se acerca la inmigración económica con la política en el nivel estadístico es en La inmigración de Europa del Este. Así ha venido sucediendo en España en los últimos af́os.

2. La conclusión a deducir de este presunto abuso, sería regular adecuadamente y de manera realista la inmigración en Europa, sin condenarla a la irregularidad ni conducirla a un callejón sin salida.

Parece que los organismos encargados de la concesión de refugio en los distintos países europeos no leyeran la prensa, ni vieran los noticiarios que nos asaltan a diario. Hábiles para impulsar unos cambios legislativos, no lo han hecho en la dirección adecuada, atendiendo a unas realidades:

- Los perseguidos políticos no dejarán de huir de sus países, de cruzar fronteras y vagar en la búsqueda de seguridad y protección.

- El cambio a impulsar pasa por dar un marco legal a los refugiados de nuestros días, ampliando la Convención del ACNUR y las legislaciones nacionales, cubriendo un gran vacio: la no contemplación de los desplazados y víctimas de las guerras. En un momento en que las guerras afectan de manera directa y general a la población civil no combatiente; cuando su persecución, desplazamiento o aniquilamiento es un arma de primera magnitud. En la Convención de Ginebra no se menciona este tipo de refugiado, pero el mismo ACNUR en todo el mundo protege mayoritariamente a víctimas de la guerra.

Años de trabajo en nuestro país y las estadísticas europeas nos confirman este hueco. La llegada masiva de iranies se fue deteniendo hasta alcanzar la paz con Irak en 1988, la inmigración de libaneses cesó con el fin de las guerras civiles en este pás, el mismo fenómeno se puede observar en Angola (con el recrudecimiento actual de las hostilidades se observa de nuevo la presencia de refugiados). Así se podrfa ir viendo en otros países donde hay o ha habido conflictos los últimos años.

A mi parecer aquí radica la necesidad de revisión de la legislación sobre la materia, tanto a nivel internacional como en los distintos países. No se puede asimilar al huido de la guerra de la antigua Yugoslavia al inmigrante económico, ni tratarlo como un solicitante de asilo abusivo. Igualmente, ¡ $c o ́ m o$ considerar inmigrante económico al ciudadano iraní que dejó atrás dos coches, su segunda residencia, sus fines de semana esquiando, su servicio doméstico, sus hijos estudiando en el extranjero y que ahora malvive de la venta ambulante en cualquier ciudad europea? Evidentemente, hay un vacio en la legislación y una falta de voluntad política de asumir las realidades y los conflictos.

Es necesario que los gobiernos europeos acepten los retos planteados y recuperen la solidaridad como valor político de primer orden. 
La Convención alude a acontecimientos acaecidos en Europa, antes del uno de enero de 1951. Superados aquellos hechos, terminada La guerra fría, caúdo el muro de Berlín, es el momento de actualizar la Convención a una nueva realidad política y dar un nuevo marco a la ingente labor humanitaria del ACNUR, tanto jurídica como socialmente.

Se hace imprescindible la revisión de la política sobre refugiados, tanto en el plano de la voluntad política como en el legislativo. Europa no supo, no pudo remediar el conflicto en la antigua Yugoslavia si que puede emprender una acción humanitaria contundente para albergar, cuando menos, a los desplazados, no contentándose como hasta ahora con cupos simbólicos. Lo que se pidio a tantos países africanos y asiáticos, que abrieran sus fronteras a las víctimas de guerras en países vecinos, no somos capaces de hacerlo en los nuestros.

Proponer un cambio en la Convención en esta dirección no supone más que acercarse a la definición que dio la OUA en 1969, entendiendo la realidad de aquel continente, una que sería una adaptación necesaria en la actualidad. Así el Convenio de la OUA extiende el concepto de refugiado a las personas que han abandonado su país a causa de agresiones externas, ocupación, dominación extranjera o incluso serios disturbios de orden público.

Con esta visión más amplia de la figura del refugiado encontrarían protección miles de refugiados en Europa que ven denegadas sus solicitudes anualmente, que no son expulsados por razones humanitarias o por carecer de un país donde ser devuelto, condenados a una inseguridad jurídica y a una marginalidad social. Las modificaciones que se van imponiendo en Europa no contemplan estas realidades que pueden perpetuar y agravar las situaciones injustas para las personas afectadas y manifiestan una insolidaridad política.

\section{Bibliografía}

CIDOB (1991). Dossier núm. 38 «La immigració». Barcelona.

EUROPEAN CONSULTATION ON REFUGEES AND EXILES (1993). Repott of ECRE biannual general meeting. Berlin.

INSERSO (1993). Boletin de Inmigración y Refugio, núm. 1, Madrid.

LOPEZ GARRIDO, Diego (1991). El derecho de asilo. Madrid: Trotta. 